\title{
Erratum to: Heavy metal enrichment in surface sediments from the SW Gulf of Mexico
}

\author{
Omar Celis-Hernández • Leticia Rosales-Hoz • Arturo Carranza-Edwards
}

Published online: 3 September 2014

(C) Springer International Publishing Switzerland 2014

\section{Erratum to: Environ Monit Assess}

\section{DOI 10.1007/s10661-013-3222-3}

The original version of this article unfortunately contained a mistake in the first author address and in the acknowledgement part.

The correct address of the first author is follows

O. Celis-Hernández

Posgrado en Ciencias del Mar y Limnología, Universidad Nacional Autónoma de México, Ciudad Universitaria, Circuito Exterior S/N, Coyoacan C.P 04510, México D.F., Mexico

The acknowledgment part should include the following paragraph.

The first author is thankful to the Consejo Nacional de Ciencia y Tecnología (CONACYT), Mexico for funding through the scholarship program (No. 209683/202662).

The online version of the article can be found at http://dx.doi.org/ 10.1007/s10661-013-3222-3.

O. Celis-Hernández

Posgrado en Ciencias del Mar y Limnología, Universidad

Nacional Autónoma de México, Ciudad Universitaria,

Circuito Exterior S/N, Coyoacan C.P 04510,

México D.F., Mexico

L. Rosales-Hoz $(\bowtie) \cdot$ A. Carranza-Edwards Instituto de Ciencias del Mar y Limnología,

Universidad Nacional Autónoma de México,

Circuito Exterior, Ciudad Universitaria, Coyoacan C.P.

04510, DF, Mexico

e-mail: mtlrhoz@gmail.com 